\title{
Ninety-four cases of encapsulated follicular variant of papillary thyroid carcinoma: A name change to Noninvasive Follicular Thyroid Neoplasm with Papillary-like Nuclear Features would help prevent overtreatment
}

\author{
Lester DR Thompson
}

Department of Pathology, Southern California Permanente Medical Group, Woodland Hills Medical Center, Woodland Hills, CA, USA

\begin{abstract}
Encapsulated follicular variant of papillary thyroid carcinoma is a common thyroid gland cancer, with a highly indolent behavior. Recently, reclassification as a non-malignant neoplasm has been proposed. There is no comprehensive, community hospital based longitudinal evaluation of encapsulated follicular variant of papillary thyroid carcinoma. Ninety-four cases of encapsulated follicular variant of papillary thyroid carcinoma were identified in a review of all thyroid gland surgeries performed in $\mathbf{2 0 0 2}$ within the Southern California Permanente Medical Group. All histology slides were reviewed and follow-up obtained. Seventy-five women and nineteen men, aged 20-80 years (mean 45.6 years), had a single $(n=61)$, multiple (same lobe; $n=20$ ), or bilateral $(n=13)$ tumor(s), ranging in size from 0.7 to $9.5 \mathrm{~cm}$ in diameter (mean $3.3 \mathrm{~cm}$ ). Histologically, all cases demonstrated a well-formed tumor capsule, with capsular and/or lymphovascular invasion in 17 and no invasion in 77 cases. Lymph node metastases were not identified. The tumors had a follicular architecture, without necrosis or $>3$ mitoses/10 high-power fields (HPFs). Classical papillary thyroid carcinoma nuclear features were seen in at least three HPFs per $3 \mathrm{~mm}$ of tumor diameter, including enlarged, elongated, crowded, and overlapping nuclei, irregular nuclear contours, nuclear grooves, and nuclear chromatin clearing. Lobectomy alone $(n=41)$, thyroidectomy alone $(n=34)$, or completion thyroidectomy $(n=19)$ was the initial treatment combined with post-op radioablative iodine in 25 patients. All patients were without evidence of disease after a median follow-up of 11.8 years. Encapsulated follicular variant of papillary thyroid carcinoma showed benign behavior, supporting conservative surgery alone and reclassification of these tumors to Noninvasive Follicular Thyroid Neoplasm with Papillary-like Nuclear Features (NIFTP).
\end{abstract}

Modern Pathology (2016) 29, 698-707; doi:10.1038/modpathol.2016.65; published online 22 April 2016

Papillary thyroid carcinoma is the most common malignant neoplasm of the thyroid gland worldwide, with excellent survival. Specific variants of papillary carcinoma are well recognized: well differentiated (classical, encapsulated, follicular, cystic, and microscopic), intermediate differentiated (tall cell, columnar cell, diffuse sclerosing, oncocytic, and insular), and poorly differentiated (presence of tumor necrosis

Correspondence: Dr LDR Thompson, MD, Department of Pathology, Southern California Permanente Medical Group, Woodland Hills Medical Center, 5601 De Soto Avenue, Woodland Hills, CA 91365, USA.

E-mail: Lester.D.Thompson@kp.org

Received 31 December 2015; revised 23 February 2016; accepted 27 February 2016; published online 22 April 2016 and increased mitoses ${ }^{1,2}$ ), which correlate with 'biologically indolent' and 'biologically aggressive' types. ${ }^{3}$ There are two forms of follicular variant: the encapsulated/well circumscribed and the infiltrative form. The encapsulated follicular variant of papillary thyroid carcinoma, characterized by an encapsulated (sometimes partial) noninvasive tumor with a nearly exclusive follicular pattern, focal to diffuse distribution of characteristic nuclear features of papillary carcinoma, a low risk of lymph node metastases, very low recurrence risk, and a strong association with $R A S$ mutations, ${ }^{1,4-7}$ has an excellent prognosis. ${ }^{1,7-20}$ Recently, reclassification of this tumor as a non-malignant neoplasm has been proposed by an international group of thyroid gland specialists, using the term Noninvasive Follicular 
Thyroid Neoplasm With Papillary-Like Nuclear Features (NIFTP). ${ }^{21}$ To date, there has not been a large, multi-institutional community practice evaluation of conservative management (surgery only without radioablative iodine or suppression therapy). This study will present clinical data, histologic findings, and patient management consequences in a retrospective review of 94 cases of encapsulated follicular variant of papillary thyroid carcinoma.

\section{Materials and methods}

All 721 patient records with thyroid surgical cases performed during 2002 at the 11 Southern California Permanente Medical Group hospitals were analyzed. Review was performed of 9999 slides including 2022 intraoperative and immunohistochemical slides, and all original and deeper sections. The 721 patients ranged in age from 0.9 to 86 years (mean 49.5 years), included 566 females and 155 males ( $\mathrm{F}: \mathrm{M}=3.7: 1$ ), and included 505 whites, 102 blacks, and 97 Asians (where race was reported). Overall, 282 (39\%) patients had non-neoplastic diseases and 439 (61\%) had neoplasms. Papillary thyroid carcinoma accounted for $74 \%$ of all neoplasms and $45 \%$ of the thyroid gland surgeries. Histologic types of papillary thyroid carcinoma were as follows: classical $(n=106 ; 33 \%$ of papillary thyroid carcinoma), microscopic/ microcarcinoma $(n=98 ; 30 \%)$, and follicular variant (encapsulated: $n=81$; invasive: $n=13 ; 30 \%$ ), among others.

This report focuses on encapsulated follicular variant of papillary thyroid carcinoma; however, Table 1 provides general data of the whole papillary thyroid carcinoma group for comparison. Encapsulated follicular variant of papillary thyroid carcinoma represented $13 \%$ of all thyroid diagnoses; $21 \%$ of all thyroid gland neoplasms; and $30 \%$ of all papillary thyroid carcinoma in this cohort. A single glass slide from 45 cases in this cohort was submitted for inclusion in the 268 cases evaluated by the consensus group for the re-examination of the encapsulated follicular variant of papillary thyroid cancer. $^{21}$

Electronic medical records were reviewed with additional information obtained as needed. Tumor recurrence was defined as any increase in serum thyroglobulin level (biochemical recurrence) or any evidence of metastatic lesion confirmed by a pathology examination (structural recurrence). This clinical investigation was conducted in accordance with all the guidelines of an Internal Review Board authorization (\#5968).

A range of 5-37 slides (often with multiple sections per slide) were examined per case, with a mean of 11.9 blocks submitted per case. The mean tumor size of $3.3 \mathrm{~cm}$ yielded an average of 3.6 blocks/ $\mathrm{cm}$ of tumor, interpreted to be satisfactory for evaluation of the tumor periphery. Data recorded: tumor focality (unifocal, multifocal [same lobe], and
Table 1 Papillary carcinoma clinical and macroscopic features

\begin{tabular}{|c|c|c|}
\hline & $\begin{array}{c}\text { Encapsulated } \\
\text { follicular variant } \\
\mathrm{n}=94(29 \%)\end{array}$ & $\begin{array}{c}\text { All papillary } \\
\text { carcinomas } \\
\mathrm{n}=324(100 \%)\end{array}$ \\
\hline \multicolumn{3}{|l|}{ Gender } \\
\hline Females $(P<0.0001)$ & 75 & 250 \\
\hline Males & 19 & 71 \\
\hline \multicolumn{3}{|l|}{ Age at presentation (years) } \\
\hline All (mean) & 45.6 & 48.4 \\
\hline All (range) & $20-80$ & $13-86$ \\
\hline$<45$ years at presentation & 46 & 128 \\
\hline$\geq 45$ years at presentation & 50 & 195 \\
\hline \multicolumn{3}{|l|}{ Location (dominant mass) } \\
\hline Right lobe & 43 & 119 \\
\hline Left lobe & 37 & 106 \\
\hline Isthmus & 0 & 4 \\
\hline Bilateral & 14 & 95 \\
\hline \multicolumn{3}{|l|}{ Size (in $\mathrm{cm}$ ) } \\
\hline Range & $0.7-9.5^{\mathrm{a}}$ & $0.1-11.6$ \\
\hline Mean $(P=0.01)$ & 3.3 & 2.3 \\
\hline \multicolumn{3}{|l|}{ Number of blocks submitted } \\
\hline Range & $5-37$ & $1-87$ \\
\hline Average & 11.9 & 12.8 \\
\hline \multicolumn{3}{|l|}{ Number of tumors } \\
\hline Single & 58 & 159 \\
\hline Multifocal (in one lobe) & 22 & 69 \\
\hline Bilateral & 14 & 96 \\
\hline If multiple, average number & 3 & 3.5 \\
\hline \multicolumn{3}{|l|}{ MACIS } \\
\hline Average (range) & $5.0(3.31-8.15)$ & $5.24(3.13-11.42)$ \\
\hline < 6 (Number/\%) & $81(86 \%)$ & $243(75 \%)$ \\
\hline 6.0-6.99 (Number/\%) & $8(9 \%)$ & $39(12 \%)$ \\
\hline 7.0-7.99 (Number/\%) & $4(4 \%)$ & $27(8 \%)$ \\
\hline 8 or higher (Number/\%) & $1(1 \%)$ & $15(5 \%)$ \\
\hline
\end{tabular}

Abbreviations: MACIS score: metastases, age, completeness of excision, invasiveness, and size.

${ }^{\mathrm{a}}$ The tumor removed was the reason for the surgery, and thus assigned a specific type even though $<1.0 \mathrm{~cm}$.

bilateral); tumor encapsulation (presence or absence; Figure 1); extrathyroidal extension (defined as tumor microscopically present within perithyroidal adipose tissue, skeletal muscle, perithyroidal nerves, adjacent to medium perithyroidal vessels); capsular invasion (tumor penetration through the capsule by $>50 \%$ of the capsule thickness); vascular invasion (tumor plugging a vascular channel within or immediately beyond the tumor capsule; tumor attached to the vessel wall; associated thrombus); lymphatic invasion; intratumoral fibrosis; architectural pattern of growth (papillary, follicular (Figures 1 and 2), solid, cystic, trabecular, and insular); irregularly shaped/ twisted/elongated follicles; presence of papillae, \% of tumor volume with papillae; psammoma bodies; tumor necrosis; increased mitotic rate $(>3 / 10$ highpower fields [HPFs]); presence of lymph nodes (perithyroidal and cervical) and presence of metastatic disease. Nuclear features of papillary thyroid 

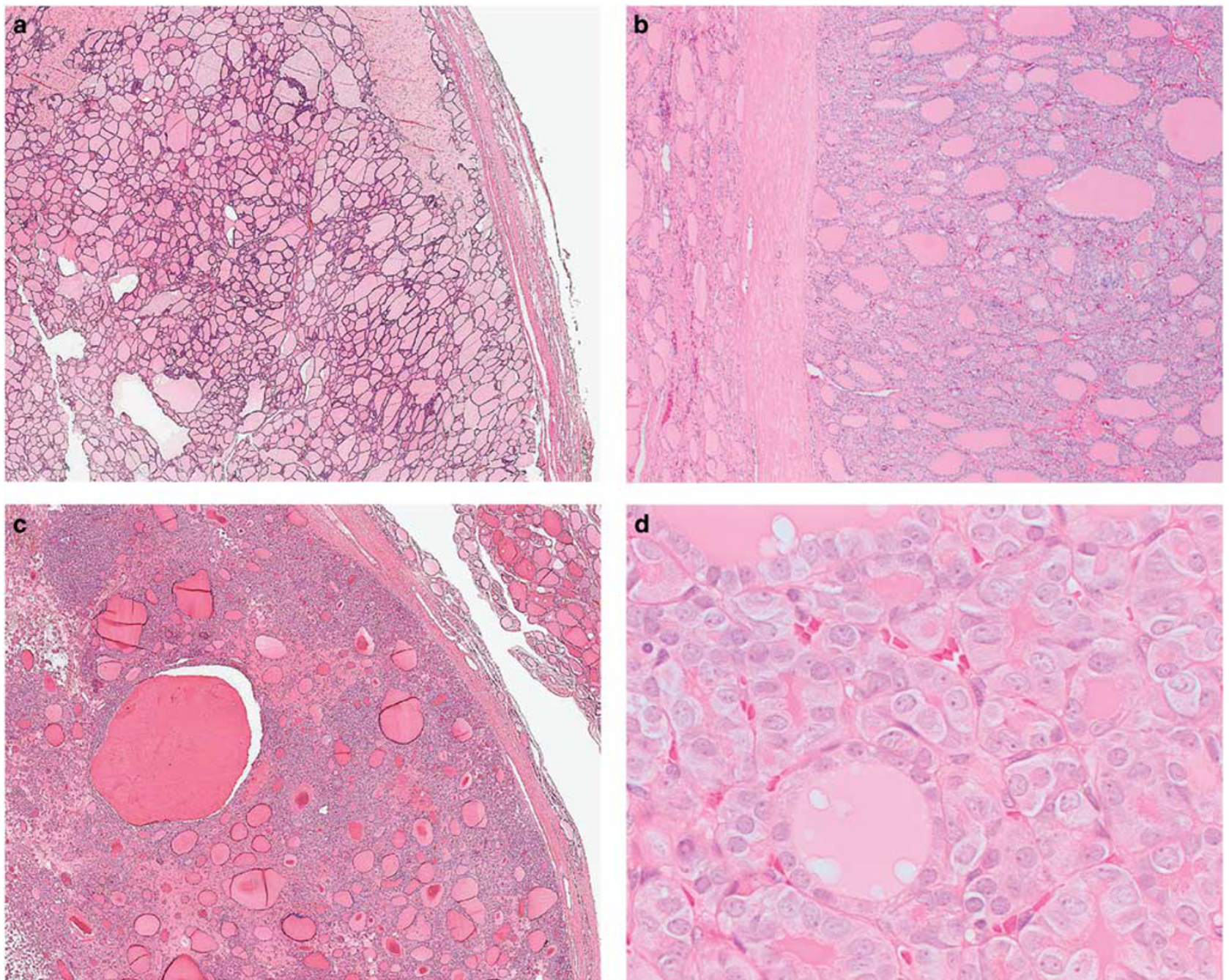

Figure 1 Variably thick capsules (a-c) around tumors with a follicular pattern and hypereosinophilic colloid. (d) Nuclear enlargement with delicate chromatin.

carcinoma included nuclear enlargement, crowding, overlapping, loss of polarity, elongation, or ovoid shape (Figure 2); irregular contours, grooves or folds; pseudoinclusions, nuclear chromatin clearing, nuclear margination, nucleoli on nuclear membranes, and even, fine, delicate nuclear chromatin (Figures 1 and 2). Nuclear features of papillary thyroid carcinoma were required in at least three foci at $\times 40$ objective magnification per $3 \mathrm{~mm}$ of linear tumor diameter, and less than $1 \%$ of tumor architecture could show papillary structures to be included in the encapsulated follicular variant of papillary thyroid carcinoma. These criteria were almost identical to the consensus group study. ${ }^{21}$ All cases were classified by the American Joint Committee on Cancer (AJCC) staging $(2010)^{22}$ criteria, although original classification was based on earlier AJCC iterations. The cases were classified by metastasis, age, completeness of resection, invasion, and size (MACIS) scoring method, using the following definitions: MACIS 3.1 (if aged $\leqslant 39$ years) or $0.08 \times$ age (if aged $>$ or $=40$ years),
$+0.3 \times$ tumor size (in centimeters), +1 (if incompletely resected), +1 (if locally invasive), +3 (if distant metastases present); $<6$ is considered excellent and $8+$ is considered poor $(<6,6-6.99,7-7.99$, and $8+$ were $99 \%, 89 \%, 56 \%$, and $24 \%$ disease-specific survival, respectively). ${ }^{23}$

$\chi^{2}$-tests and Fisher's Exact tests were performed to compare observed and expected frequency distributions. Unpaired $t$-tests or one-way analysis of variance were used to compare the means between groups. Confidence intervals of $95 \%$ were generated for all positive findings. The alpha level was set at $P<0.05$.

\section{Results}

\section{Clinical Findings}

There were 75 females and 19 males (Table 1), ranging from 20 to 80 years (median 46 years). Four 

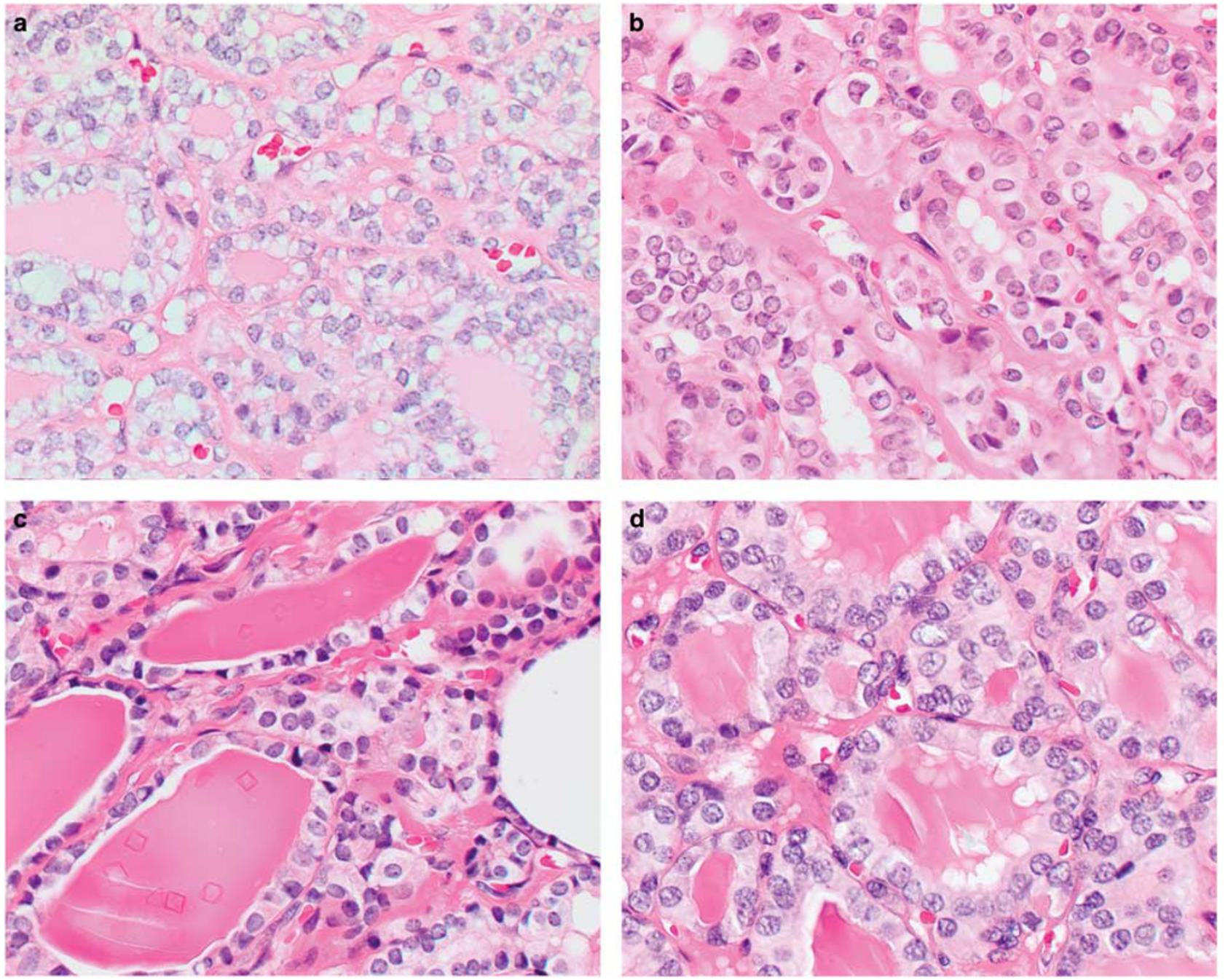

Figure 2 Histologic features of encapsulated follicular variant of papillary thyroid carcinoma including (a, b) cellular enlargement, nuclear enlargement and elongation, nuclear overlapping and crowding, optical clearing, nuclear grooves, contour irregularities, and delicate chromatin; (c, d) hypereosinophilic scalloped colloid and crystalloids.

tumors were found incidentally during evaluation for hyperparathyroidism.

\section{Pathologic Features}

Macroscopic. The encapsulated follicular variants of papillary thyroid carcinomas were bilateral (15\%), multicentric (one lobe, 23\%), or unicentric (62\%). In 28 of 36 patients with multifocal tumors, the additional tumor was microscopic $(<1 \mathrm{~cm}$ by definition), with a range of one to eight additional tumors, whereas eight patients had a second tumor of $>1 \mathrm{~cm}$. Compared with all papillary thyroid carcinomas $(n=324), 96$ tumors were bilateral $(30 \%), 69$ were multiple $(21 \%)$, and 159 were unifocal (single, 49\%). Therefore, $51 \%$ of all papillary thyroid carcinomas were multifocal.

The tumors varied from 0.7 to $9.5 \mathrm{~cm}$ in greatest diameter (mean $3.3 \mathrm{~cm}$; median $3.0 \mathrm{~cm}$ ). Five microcarcinomas in this group were the reason for the surgery (ie, not incidental), with the patients evaluated for a single mass. The encapsulated follicular variant of the papillary thyroid carcinoma group had statistically significantly larger tumors $(P=0.01)$ than classical papillary carcinoma (mean $2.7 \mathrm{~cm})$.

Microscopic. The tumors were all encapsulated (Table 2) and were divided into 24 'invasive' and 77 'noninvasive' tumors, without any MACIS scoring differences between the groups. All of the cases in this cohort showed a well-developed fibrous connective tissue capsule (no cases showed only partial encapsulation or only well-circumscribed tumors). Capsular invasion was identified in 11 tumors (2-14 foci of invasion, mean 6.6 per case). Fourteen tumors showed lymphovascular invasion (two to seven foci of invasion, mean 3.6 per case). Extrathyroidal extension was identified in only one 
case, but in a second, topographically distinct, microscopic classical tumor. The margins were positive in $5 \%$ of cases. No metastatic disease was identified in patients with either central compartment or lateral neck lymph node dissections. The majority of patients $(n=52,55 \%)$ did not have any lymph node samplings. All patients were stratified into MACIS score groups (Table 1), with $86 \%$ in the $<6$ group and only one patient in the 8 or higher group.

The architecture was follicular by definition, with only rare or isolated papillae noted. No cases demonstrated histologic features of other known papillary thyroid carcinoma variants (eg, tall cell, columnar, oncocytic, insular or cribriform variants), nor were any tumors poorly differentiated (solid pattern; tumor necrosis present; increased mitoses of $>3 / 10$ HPFs). The cells ranged from slightly flattened to cuboidal to columnar cells, showing an increased nuclear to cytoplasmic ratio and enlargement when compared to the uninvolved adjacent

Table 2 Microscopic features of encapsulated follicular variant of papillary thyroid carcinoma and tumor staging

\begin{tabular}{lc}
\hline Feature & Number \\
\hline Capsular invasion present & 11 \\
Lymphovascular invasion present & 14 \\
Extracapsular extension present & 1 \\
Margin status positive & 5 \\
Lymph node status (sampled and negative) & 42 \\
Tumor T stage & \\
pT1 & 29 \\
pT1a & 5 \\
pT1b & 24 \\
pT2 & 38 \\
pT3 & 27 \\
Tumor N stage & \\
pNx & \\
pNo & 52 \\
Overall AJCC group & 42 \\
I & \\
II & 61 \\
\hline
\end{tabular}

Abbreviation: AJCC, American Joint Committee on Cancer. thyroid parenchyma. The nuclear features of papillary thyroid carcinoma were present (see Materials and Methods; identical to consensus criteria ${ }^{21}$ ), although the features were not uniformly present. Although preferentially identified at the tumor to capsule junction, they were frequently a focal finding. However, if at least three HPFs within a 3-mm linear area of tumor (diameter measure) showed these features, then the entire encapsulated nodule was diagnosed as an encapsulated follicular variant of papillary thyroid carcinoma, a convention used by others. ${ }^{24,25}$

Other thyroid gland diseases were noted: adenomatoid nodules (78\%) and chronic lymphocytic thyroiditis $(42 \%)$. Parathyroid gland tissue was detected in $25 \%$, confirming inadvertent removal is common.

\section{Clinical Treatment and Patient Outcome}

See Table 3 for management protocols. Most patients were managed by surgery only $(n=69)$, with the remainder managed by surgery and by ${ }^{131} \mathrm{I}$ radiotherapy $(n=25)$. Of those with surgery only, the median survival was 11.8 years without any events. Surgical procedures included lobectomy only $(n=42)$, thyroidectomy only $(n=21)$, thyroidectomy with lymph node dissection $(n=1)$, or a completion thyroidectomy after the original diagnosis without ${ }^{131}$ I radiotherapy $(n=5)$. There was no lymph node metastases in 42 patients with lymph node sampling. Those managed by follow-up radioactive iodine ablation $(n=25)$ treatment had a mean dose of $139 \mathrm{mCi}$ (range $28.9-200 \mu \mathrm{Ci}{ }^{131} \mathrm{I}$ ). Despite various management protocols, outcomes were identical.

Extrathyroidal extension was noted in one patient (by definition, pT3). There were no stage IV tumors (Table 2).

There was $100 \%$ patient follow-up with no evidence of recurrence based on biochemical or structural disease at the last follow-up: median 11.8 years (mean 11.2; range 1.2-12.5 years): alive $(n=92)$ or dead $(n=2)$. Outcomes were identical regardless of parameter: gender, age, tumor size, multifocality, presence of capsular or lymphovascular invasion, lymph node status, and stage or treatment.

Table 3 Patient management and outcome

\begin{tabular}{|c|c|c|}
\hline Treatment & Number of patients & Mean years of follow-up \\
\hline Lobectomy alone & 42 & 11.3 \\
\hline Invasive type: LVI and/or capsular invasion & 4 & 11.5 \\
\hline Thyroidectomy alone & 21 & 11.6 \\
\hline Invasive type: LVI and/or capsular invasion & 7 & 11.4 \\
\hline Thyroidectomy and lymph node dissection only & 1 & 11.7 \\
\hline Completion thyroidectomy only & 5 & 11.1 \\
\hline Surgery and radioablative iodine & 25 & 10.6 \\
\hline Surgery alone & 69 & 11.6 \\
\hline \multicolumn{3}{|c|}{$\begin{array}{l}\text { Median follow-up, } 11.8 \text { years; median age, } 46 \text {; F:M, } 55: 14 \text {; } \\
\text { median tumor size, } 3.0 \text {; Stage I/II/III/IV: } 44 / 14 / 11 / 0 \text {; } \\
\text { no lymph node metastases, no recurrence and no distant metastases }\end{array}$} \\
\hline
\end{tabular}




\section{Discussion}

Papillary thyroid carcinoma has several wellrecognized histologic variants, with follicular variant a common type as defined by the World Health Organization. ${ }^{3}$ There are two main types: encapsulated and infiltrative (macrofollicular and diffuse follicular variants are rare types not considered here). The term 'encapsulated papillary carcinoma' is applied to classical papillary carcinoma with a well-formed capsule, ${ }^{26,27}$ showing a dominant papillary rather than follicular architecture. The follicular variant comprises $\sim 22-34 \%$ of all papillary carcinomas (including this clinical series). ${ }^{13,28,29}$ The biologic behavior of encapsulated and nonencapsulated or partially encapsulated but wellcircumscribed tumors are equivalent. ${ }^{13,18}$ Thus, the two types of follicular variant tumors (encapsulated and infiltrative) are biologically and histologically distinctive. The encapsulated/well-circumscribed form may occasionally display invasion (as in this series), showing a genotype that resembles follicular adenoma and/or follicular carcinoma (RAS mutations); while the infiltrative form lacks circumscription, shows a total or partial lack of a capsule, characterized by neoplastic follicles infiltrating between non-neoplastic ones, more frequently showing $B R A F$ mutations, and showing a greater metastatic potential and higher risk of recurrence, similar to classical papillary thyroid carcinoma. ${ }^{2,13-15}$

Encapsulated follicular variant of papillary thyroid carcinoma affects a similar age group as classical papillary carcinoma, with a 45.6 year mean in this cohort versus a 44.0 year mean in compiled literature (Table 4). Patients $<45$ years have a more favorable prognosis. For encapsulated follicular variant of papillary thyroid carcinoma, no patients in this series had disease at the last follow-up. Compiled literature of reported follicular variant papillary thyroid carcinoma cases (invasive or noninvasive) showed that $3.0 \%$ had disease at last follow-up, but approached zero for the noninvasive category (Table 4).

This study correlated with the MACIS score categorization (Table 2), averaging a score of 5.0 for the encapsulated follicular variant of papillary thyroid carcinoma category, matching the predicted outcome of a $99 \%$ cause specific 21-year survival rate.

No encapsulated follicular variant of papillary thyroid carcinoma case in this series had an adverse outcome. However, when combined with cases reported in the literature, completely encapsulated or partially encapsulated tumors showed a much better outcome than invasive tumors. For follicular variant papillary thyroid carcinoma, the outcome was better than for classical papillary thyroid carcinoma. This clinical study showed no lymph node metastases. The literature reported $12 \%$ lymph node metastasis (Table 4), much lower than rates for classical papillary thyroid carcinoma or other variant types but metastases were only identified in tumors with invasion.
Encapsulated follicular variant of papillary thyroid carcinoma is diagnosed based on hematoxylin and eosin stained slides. This tumor tends to genotypically cluster with other follicular patterned tumors rather than classical papillary thyroid carcinoma. 1,5,7,13,30-32 The Cancer Genome Atlas for papillary thyroid carcinoma identified most classical papillary thyroid carcinoma clustered with $B R A F$ V600E-type tumors, without overlapping with the $R A S$ or PAX8/PPAR cluster of tumors. ${ }^{6}$ Both $R A S$ $(H, N$, or $K R A S)$ or $P A X 8 / P P A R \gamma$ is seen in thyroid follicular-patterned tumors: follicular adenoma, follicular carcinoma, and follicular variant of papillary thyroid carcinoma. Therefore, follicular-patterned tumors can have similar molecular findings, even though nuclear features may be different. Histopathologic, clinical, and molecular data suggest that the follicular variant of papillary thyroid carcinoma is actually two lesions: (1) the noninvasive, partially or completely encapsulated follicular variant papillary thyroid carcinoma (genotypic and behavioral profile similar to follicular adenoma/carcinoma) and (2) invasive (including infiltrative type) follicular variant papillary thyroid carcinoma (genotypic and behavior profile similar to classical papillary thyroid carcinoma, including the BRAF mutation status). ${ }^{5,7,13,31}$ Well-circumscribed tumors, whether encapsulated or not, 'noninvasive' follicular variant papillary thyroid carcinoma-type tumors have an exceedingly indolent clinical behavior.

Total thyroidectomy with neck exploration and follow-up radioactive iodine therapy is advocated for biologically aggressive types of thyroid carcinoma, including aggressive variants of papillary carcinoma. $^{33}$ In this series, two patients $(2 \%)$ developed permanent hypocalcemia, whereas none had permanent nerve damage. In this cohort and in identical noninvasive tumors reported in the literature, there was no evidence of metastatic disease (structural or biochemical). ${ }^{12}$ Follow-up (mean 11.2 years) showed a complete lack of latent or unrecognized disease and no need for prophylactic central lymph node dissection for this tumor type.

The level of serum Tg is related proportionately to the amount of neoplastic thyroid tissue. ${ }^{34}$ Therefore, in patients managed by surgery only (without radioactive iodine), neck ultrasonography is highly sensitive, while using 'stable' Tg levels as a guide. Only an increase in serum Tg should prompt further investigation. ${ }^{35}$

Previous studies have concluded that adequate therapy for encapsulated follicular variant of papillary thyroid carcinoma should be a lobectomy $y^{35-37}$ without radioactive iodine.1,12,14,15,29 Radioactive iodine should be employed only when a clinical benefit can be reasonably expected which cannot be shown for this tumor type, and thus should be avoided.

Before this series, case numbers have been small, shown referral bias, had short follow-up periods, and/or patients lost to follow-up. On the basis of this clinical study, together with a compilation of 
Table 4 Literature summary of encapsulated follicular variant of papillary thyroid carcinoma

\begin{tabular}{|c|c|c|c|c|c|c|c|c|c|c|c|c|c|c|c|c|}
\hline Author & $F V$ & Male & Female & Age & Size & Single & Multifocal & Encap & $\begin{array}{l}\text { Capsular } \\
\text { invasion }\end{array}$ & $\begin{array}{l}\text { Vascular } \\
\text { invasion }\end{array}$ & ETE & $\begin{array}{l}\text { Central LN } \\
\text { metastases }\end{array}$ & $\begin{array}{l}\text { Follow-up } \\
\text { number }\end{array}$ & Recurrence & Metastases & $\begin{array}{l}\text { Follow-up in } \\
\text { years (mean) }\end{array}$ \\
\hline Hawk $^{46}$ & 15 & 4 & 11 & 40 & $\mathrm{n} / \mathrm{r}$ & $\mathrm{n} / \mathrm{r}$ & $\mathrm{n} / \mathrm{r}$ & 15 & 15 & $\mathrm{n} / \mathrm{r}$ & $\mathrm{n} / \mathrm{r}$ & 3 & 15 & 0 & 1 & 7.3 \\
\hline Schroder ${ }^{47}$ & 6 & 1 & 5 & 44 & 2.5 & 6 & $\mathrm{n} / \mathrm{r}$ & 6 & 6 & 4 & $\mathrm{n} / \mathrm{r}$ & 3 & 6 & 0 & 0 & 5.3 \\
\hline Carcangiu $^{29}$ & 25 & 7 & 18 & 41 & $\mathrm{n} / \mathrm{r}$ & $\mathrm{n} / \mathrm{r}$ & $\mathrm{n} / \mathrm{r}$ & 16 & $\mathrm{n} / \mathrm{r}$ & $\mathrm{n} / \mathrm{r}$ & 0 & 8 & 21 & 2 & 0 & $\mathrm{n} / \mathrm{r}$ \\
\hline Tielens ${ }^{45}$ & 37 & 10 & 27 & 44 & 1.2 & 11 & 26 & 11 & 28 & 3 & 6 & 8 & 37 & 0 & 1 & 2.8 \\
\hline Moreno ${ }^{48}$ & 25 & 4 & 21 & 36 & $\mathrm{n} / \mathrm{r}$ & 20 & 5 & 25 & $\mathrm{n} / \mathrm{r}$ & 0 & $\mathrm{n} / \mathrm{r}$ & 3 & 25 & 0 & 0 & 9 \\
\hline Jain ${ }^{49}$ & 71 & $\mathrm{n} / \mathrm{r}$ & $\mathrm{n} / \mathrm{r}$ & 41 & 2.8 & 53 & 18 & 20 & $\mathrm{n} / \mathrm{r}$ & 5 & 9 & 4 & $\mathrm{n} / \mathrm{r}$ & $\mathrm{n} / \mathrm{r}$ & $\mathrm{n} / \mathrm{r}$ & $\mathrm{n} / \mathrm{r}$ \\
\hline $\mathrm{Zhu}^{31}$ & 30 & 9 & 21 & 42 & 3.4 & $\mathrm{n} / \mathrm{r}$ & $\mathrm{n} / \mathrm{r}$ & 15 & $\mathrm{n} / \mathrm{r}$ & 6 & 4 & 4 & $\mathrm{n} / \mathrm{r}$ & 0 & 1 & $\mathrm{n} / \mathrm{r}$ \\
\hline Passler $^{50}$ & 37 & 6 & 31 & 49 & 1.7 & 25 & 12 & $\mathrm{n} / \mathrm{r}$ & $\mathrm{n} / \mathrm{r}$ & $\mathrm{n} / \mathrm{r}$ & 5 & 12 & 37 & 0 & 0 & 10.7 \\
\hline Zidan $^{43}$ & 100 & 26 & 74 & 44 & 3.5 & 67 & 33 & $\mathrm{n} / \mathrm{r}$ & 38 & $\mathrm{n} / \mathrm{r}$ & $\mathrm{n} / \mathrm{r}$ & 22 & 100 & $\mathrm{n} / \mathrm{r}$ & 8 & 11.5 (d) \\
\hline Burningham ${ }^{44}$ & 46 & 7 & 39 & 46 & 1.5 & 26 & 18 & 46 & 0 & 6 & 0 & 4 & 45 & 0 & 0 & 3.2 \\
\hline Lang $^{51}{ }^{\circ}$ & 67 & 10 & 57 & 39 & 2.5 & 47 & 20 & $\mathrm{n} / \mathrm{r}$ & 25 & 9 & 18 & 18 & 67 & 6 & 3 & 11.3 \\
\hline Chang ${ }^{52}$ & 85 & 17 & 68 & 43 & 2.7 & $\mathrm{n} / \mathrm{r}$ & $\mathrm{n} / \mathrm{r}$ & $\mathrm{n} / \mathrm{r}$ & $\mathrm{n} / \mathrm{r}$ & $\mathrm{n} / \mathrm{r}$ & 10 & 10 & 85 & 12 & 10 & 4.5 \\
\hline Hagag 38 & 92 & 13 & 79 & 46 & $\mathrm{n} / \mathrm{r}$ & 50 & 42 & $\mathrm{n} / \mathrm{r}$ & $\mathrm{n} / \mathrm{r}$ & 11 & 35 & 29 & 26 & 14 & 15 & 9.5 \\
\hline di Cristofaro ${ }^{53}$ & 24 & 8 & 16 & 39 & 2.2 & $\mathrm{n} / \mathrm{r}$ & $\mathrm{n} / \mathrm{r}$ & 21 & $\mathrm{n} / \mathrm{r}$ & 12 & $\mathrm{n} / \mathrm{r}$ & 7 & $\mathrm{n} / \mathrm{r}$ & $\mathrm{n} / \mathrm{r}$ & 0 & $\mathrm{n} / \mathrm{r}$ \\
\hline $\mathrm{Liu}^{14}$ & 78 & 12 & 49 & 43 & 2.5 & $\mathrm{n} / \mathrm{r}$ & $\mathrm{n} / \mathrm{r}$ & 61 & 14 & 10 & 3 & 3 & 42 & 0 & 0 & 11.1 (d) \\
\hline Yuksel $^{54}$ & 41 & 11 & 30 & $\mathrm{n} / \mathrm{r}$ & 1.7 & 37 & 4 & $\mathrm{n} / \mathrm{r}$ & $\mathrm{n} / \mathrm{r}$ & $\mathrm{n} / \mathrm{r}$ & $\mathrm{n} / \mathrm{r}$ & 0 & $\mathrm{n} / \mathrm{r}$ & 0 & 0 & $\mathrm{n} / \mathrm{r}$ \\
\hline Widder ${ }^{20}$ & 82 & 31 & 154 & 44 & 3.1 & $\mathrm{n} / \mathrm{r}$ & $\mathrm{n} / \mathrm{r}$ & $\mathrm{n} / \mathrm{r}$ & $\mathrm{n} / \mathrm{r}$ & $\mathrm{n} / \mathrm{r}$ & $\mathrm{n} / \mathrm{r}$ & $\mathrm{n} / \mathrm{r}$ & 79 & 0 & 0 & 9.3 \\
\hline Rivera $^{15}$ & 63 & 23 & 40 & 43 & 3.1 & $\mathrm{n} / \mathrm{r}$ & $\mathrm{n} / \mathrm{r}$ & 63 & 24 & 16 & 0 & 2 & 63 & 0 & 4 & 8.9 (d) \\
\hline Gupta $^{55}$ & 41 & 6 & 16 & 47 & 1.7 & $\mathrm{n} / \mathrm{r}$ & $\mathrm{n} / \mathrm{r}$ & 22 & $\mathrm{n} / \mathrm{r}$ & 1 & 0 & 0 & $\mathrm{n} / \mathrm{r}$ & $\mathrm{n} / \mathrm{r}$ & $\mathrm{n} / \mathrm{r}$ & $\mathrm{n} / \mathrm{r}$ \\
\hline Baloch $^{8}$ & 56 & 13 & 43 & 46 & $\mathrm{n} / \mathrm{r}$ & 30 & 26 & 56 & 10 & 2 & 4 & 4 & 34 & 2 & 1 & $9(\mathrm{~d})$ \\
\hline Boler $^{9}$ & 15 & $\mathrm{n} / \mathrm{r}$ & $\mathrm{n} / \mathrm{r}$ & $\mathrm{n} / \mathrm{r}$ & $\mathrm{n} / \mathrm{r}$ & $\mathrm{n} / \mathrm{r}$ & $\mathrm{n} / \mathrm{r}$ & 15 & 1 & 1 & $\mathrm{n} / \mathrm{r}$ & 1 & $\mathrm{n} / \mathrm{r}$ & $\mathrm{n} / \mathrm{r}$ & $\mathrm{n} / \mathrm{r}$ & $\mathrm{n} / \mathrm{r}$ \\
\hline Vivero $^{18}$ & 77 & 11 & 66 & 50 & 2.4 & 69 & 8 & 62 & 8 & 5 & 1 & 0 & 66 & 1 & 0 & 8.3; 9.3 (d) \\
\hline Howitt $^{13}$ & 28 & 5 & 23 & 49 & 2.4 & 11 & 17 & 28 & 0 & 0 & 0 & 0 & 28 & 0 & 0 & $5.3 ; 6.1$ (d) \\
\hline Rosario $^{17}$ & 57 & 10 & 47 & 45 & 2.9 & 54 & 3 & 57 & 0 & 0 & 0 & 0 & 57 & 0 & 0 & 6 (d) \\
\hline Finnerty 11 & 119 & 31 & 61 & 48 & 1.6 & 90 & 29 & 92 & $\mathrm{n} / \mathrm{r}$ & 6 & 0 & 19 & 119 & 0 & 0 & $2.2(\mathrm{~d})$ \\
\hline Walts $^{19}$ & 48 & 11 & 37 & 51 & 1.2 & 19 & 29 & 22 & $\mathrm{n} / \mathrm{r}$ & $\mathrm{n} / \mathrm{r}$ & 20 & 10 & 45 & 4 & 1 & 2.7 (d) \\
\hline Ganly $^{12}$ & 83 & 15 & 42 & 48 & 3.0 & $\mathrm{n} / \mathrm{r}$ & $\mathrm{n} / \mathrm{r}$ & 57 & 0 & 0 & 0 & 0 & 83 & 0 & 0 & 9.5 (d) \\
\hline Totals & 1448 & 301 & 1075 & 44 & 2.5 & 615 & 290 & 710 & & & & 174 & & 27 & 45 & \\
\hline
\end{tabular}

Abbreviations: (d), Median; Encap, partially or completely encapsulated; ETE, extrathyroidal extension; FV, follicular variant; FU, number of patients with follow-up; LN, lymph node; n/r, not reported. 
the literature (Table 4), there is strong evidence that no additional intervention is required. Noninvasive, partially to completely encapsulated follicular variant papillary carcinomas as a group have exceedingly indolent behavior and do not require completion thyroidectomy or radioactive iodine therapy. Cases of biologically aggressive encapsulated follicular variant of papillary thyroid carcinoma ${ }^{38-40}$ have been reported, but these included tumors with extrathyroidal extension or invasion, and lacked information about encapsulation or multifocality, features which each predict more biologically aggressive behavior independent of histologic variant. On the basis of the American Thyroid Association 'Risk Continuum' or 'Risk Stratification', the tumor would fit in at the lowest point on the continuum, matching the recommendations of initial surgery alone. ${ }^{41}$ 'The Endocrine Pathology Society Conference for Re-examination of the Encapsulated Follicular Variant of Papillary Thyroid Cancer' was convened 20-21 March 2015 in Boston, MA, USA, and based on extensive evaluation of cases, outcome data, and the development of a set of inclusion and exclusion criteria, issued a new name: Noninvasive Follicular Thyroid Neoplasm with Papillary-like Nuclear Features (NIFTP).

\section{Conclusion}

Adopting a new term for noninvasive encapsulated follicular variant of papillary thyroid carcinoma, a tumor with an indolent outcome in the vast majority of cases, might avoid overtreatment and not unduly burden patients with a cancer diagnosis and potential lifelong follow-up. Rapid adoption of the proposed new term, Noninvasive Follicular Thyroid Neoplasm with Papillary-like Nuclear Features (NIFTP), will enhance appropriate risk stratification and management of these patients rather than the current 'one size fits all' approach. Whereas there is a small potential for distant metastases in invasive tumors, ${ }^{8,15,39,42-45}$ the noninvasive follicular thyroid neoplasm with papillary-like nuclear features (formerly encapsulated follicular variant of papillary thyroid carcinoma without invasion) are exceedingly indolent tumors, best managed conservatively by lobectomy or thyroidectomy alone, without radioablative iodine or suppression therapy.

\section{Disclosure/conflict of interest}

The author declares no conflict of interest.

\section{Disclaimer}

The opinions or assertions contained herein are the private views of the author and are not to be construed as official or as reflecting the views of Southern California Permanente Medical Group.
Presented at the $103^{\text {rd }}$ Annual Meeting of the United States and Canadian Academy of Pathology, Boston, MA, USA 24 March 2015.

\section{References}

1 Ghossein R. Encapsulated malignant follicular cellderived thyroid tumors. Endocr Pathol 2010;21: 212-218.

2 Rivera M, Ricarte-Filho J, Patel S et al. Encapsulated thyroid tumors of follicular cell origin with high grade features (high mitotic rate/tumor necrosis): a clinicopathologic and molecular study. Hum Pathol 2010;41: 172-180.

3 LiVolsi VA, Albores-Saavedra J, Asa SL et al. Papillary carcinoma. In: DeLellis RA, Lloyd RV, Heitz PU et al. (eds). Pathology and Genetics of Tumours of Endocrine Organs, 3rd edn. IARC Press: Lyon, France, 2004, pp 57-66.

4 Nikiforov YE, Nikiforova MN. Molecular genetics and diagnosis of thyroid cancer. Nat Rev Endocrinol 2011;7: 569-580.

5 Nikiforova MN, Nikiforov YE. Molecular genetics of thyroid cancer: implications for diagnosis, treatment and prognosis. Expert Rev Mol Diagn 2008;8:83-95.

6 Cancer Genome Atlas Research Network. Integrated genomic characterization of papillary thyroid carcinoma. Cell 2014;159:676-690.

7 Rivera M, Ricarte-Filho J, Knauf J et al. Molecular genotyping of papillary thyroid carcinoma follicular variant according to its histological subtypes (encapsulated vs infiltrative) reveals distinct BRAF and RAS mutation patterns. Mod Pathol 2010;23:1191-1200.

8 Baloch ZW, Shafique K, Flannagan M et al.Encapsulated classic and follicular variants of papillary thyroid carcinoma: comparative clinicopathologic study. Endocr Pract 2010;16:952-959.

9 Boler A, Chattopadhyay S, Mallick J et al.Encapsulated follicular variant papillary thyroid carcinoma: problems in histological diagnosis. J Indian Med Assoc 2012;110:536-540.

10 Chan JK. Papillary carcinoma of thyroid: classical and variants. Histol Histopathol 1990;5:241-257.

11 Finnerty BM, Kleiman DA, Scognamiglio $\mathrm{T}$ et al. Navigating the management of follicular variant papillary thyroid carcinoma subtypes: a classic PTC comparison. Ann Surg Oncol 2015;22:1200-1206.

12 Ganly I, Wang L, Tuttle RM et al. Invasion rather than nuclear features correlates with outcome in encapsulated follicular tumors: further evidence for the reclassification of the encapsulated papillary thyroid carcinoma follicular variant. Hum Pathol 2015;46:657-664.

13 Howitt BE, Jia Y, Sholl LM et al.Molecular alterations in partially-encapsulated or well-circumscribed follicular variant of papillary thyroid carcinoma. Thyroid 2013;23:1256-1262.

14 Liu J, Singh B, Tallini G et al. Follicular variant of papillary thyroid carcinoma: a clinicopathologic study of a problematic entity. Cancer 2006;107:1255-1264.

15 Rivera M, Tuttle RM, Patel S et al. Encapsulated papillary thyroid carcinoma: a clinico-pathologic study of 106 cases with emphasis on its morphologic subtypes (histologic growth pattern). Thyroid 2009;19: 119-127. 
16 Rosai J. The encapsulated follicular variant of papillary thyroid carcinoma: back to the drawing board. Endocr Pathol 2010;21:7-11.

17 Rosario PW, Penna GC, Calsolari MR. Noninvasive encapsulated follicular variant of papillary thyroid carcinoma: is lobectomy sufficient for tumours $>/=1 \mathrm{~cm}$ ? Clin Endocrinol (Oxf) 2014;81:630-632.

18 Vivero M, Kraft S, Barletta JA. Risk stratification of follicular variant of papillary thyroid carcinoma. Thyroid 2013;23:273-279.

19 Walts AE, Mirocha JM, Bose S. Follicular variant of papillary thyroid carcinoma (FVPTC): histological features, BRAF V600E mutation, and lymph node status. J Cancer Res Clin Oncol 2015;1414:1749-1756.

20 Widder S, Guggisberg K, Khalil M et al.A pathologic rereview of follicular thyroid neoplasms: the impact of changing the threshold for the diagnosis of the follicular variant of papillary thyroid carcinoma. Surgery 2008;144:80-85.

21 Nikiforov YE, Seethala RR, Tallini G et al. Nomenclature Revision for Encapsulated Follicular Variant of Papillary Thyroid Carcinoma: A Paradigm Shift to Reduce Overtreatment of indolent tumors. JAMA Oncol 2016;2 (in press).

22 Edge S, Byrd DR, Compton CC et al.AJCC Cancer Staging Manual, 7th edn. Springer, 2010, pp 87-96.

23 Hay ID, Bergstralh EJ, Goellner JR et al.Predicting outcome in papillary thyroid carcinoma: development of a reliable prognostic scoring system in a cohort of 1779 patients surgically treated at one institution during 1940 through 1989. Surgery 1993;114:1050-1057.

24 Guney G, Tezel GG, Kosemehmetoglu K et al. Molecular features of follicular variant papillary carcinoma of thyroid: comparison of areas with or without classical nuclear features. Endocr Pathol 2014;25: 241-247.

25 Tallini G, Brandao G. Assessment of RET/PTC oncogene activation in thyroid nodules utilizing laser microdissection followed by nested RT-PCR. Methods Mol Biol 2005;293:103-111.

26 Evans HL. Encapsulated papillary neoplasms of the thyroid. A study of 14 cases followed for a minimum of 10 years. Am J Surg Pathol 1987;11:592-597.

27 Oyama T, Ishida T, Ishii K et al. Encapsulated papillary carcinoma of the thyroid gland: clinicopathological and cytofluorometric study in comparison with nonencapsulated papillary carcinoma. Acta Pathol Jpn 1993;43:516-521.

28 Daniels GH. What if many follicular variant papillary thyroid carcinomas are not malignant? A review of follicular variant papillary thyroid carcinoma and a proposal for a new classification. Endocr Pract 2011;17: $768-787$

29 Carcangiu ML, Zampi G, Pupi A et al.Papillary carcinoma of the thyroid. A clinicopathologic study of 241 cases treated at the University of Florence. Italy Cancer 1985;55:805-828.

30 Armstrong MJ, Yang H, Yip L et al. PAX8/PPARgamma rearrangement in thyroid nodules predicts follicularpattern carcinomas, in particular the encapsulated follicular variant of papillary carcinoma. Thyroid 2014;24:1369-1374.

31 Zhu Z, Gandhi M, Nikiforova MN et al.Molecular profile and clinical-pathologic features of the follicular variant of papillary thyroid carcinoma. An unusually high prevalence of ras mutations. Am J Clin Pathol 2003;120:71-77.
32 Lee SR, Jung CK, Kim TE et al. Molecular genotyping of follicular variant of papillary thyroid carcinoma correlates with diagnostic category of fine-needle aspiration cytology: values of RAS mutation testing. Thyroid 2013;23:1416-1422.

33 Carling T, Ocal IT, Udelsman R. Special variants of differentiated thyroid cancer: does it alter the extent of surgery versus well-differentiated thyroid cancer? World J Surg 2007;31:916-923.

34 Bachelot A, Cailleux AF, Klain M et al. Relationship between tumor burden and serum thyroglobulin level in patients with papillary and follicular thyroid carcinoma. Thyroid 2002;12:707-711.

35 Kloos RT. Papillary thyroid cancer: medical management and follow-up. Curr Treat Options Oncol 2005;6: 323-338.

36 Kuriakose MA, Hicks WL Jr., Loree TR et al.Risk groupbased management of differentiated thyroid carcinoma. J R Coll Surg Edinb 2001;46:216-223.

37 Patel SS, Goldfarb M. Well-differentiated thyroid carcinoma: the role of post-operative radioactive iodine administration. J Surg Oncol 2013;107:665-672.

38 Hagag P, Hod N, Kummer E et al. Follicular variant of papillary thyroid carcinoma: clinical-pathological characterization and long-term follow-up. Cancer J 2006;12:275-282.

39 Baloch ZW, LiVolsi VA. Encapsulated follicular variant of papillary thyroid carcinoma with bone metastases. Mod Pathol 2000;13:861-865.

40 Loureiro MM, Leite VH, Boavida JM et al. An unusual case of papillary carcinoma of the thyroid with cutaneous and breast metastases only. Eur J Endocrinol 1997;137:267-269.

41 Haugen BR, Alexander EK, Bible KC et al. 2015 American Thyroid Association Management Guidelines for Adult Patients with Thyroid Nodules and Differentiated Thyroid Cancer. The American Thyroid Association (ATA) Guidelines Task Force on Thyroid Nodules and Differentiated Thyroid Cancer. Thyroid 2016;26:1-133.

42 Hunt JL, Dacic S, Barnes EL et al.Encapsulated follicular variant of papillary thyroid carcinoma. Am J Clin Pathol 2002;118:602-603.

43 Zidan J, Karen D, Stein M et al. Pure versus follicular variant of papillary thyroid carcinoma: clinical features, prognostic factors, treatment, and survival. Cancer 2003;97:1181-1185.

44 Burningham AR, Krishnan J, Davidson BJ et al.Papillary and follicular variant of papillary carcinoma of the thyroid: Initial presentation and response to therapy. Otolaryngol Head Neck Surg 2005;132:840-844.

45 Tielens ET, Sherman SI, Hruban RH et al.Follicular variant of papillary thyroid carcinoma. A clinicopathologic study. Cancer 1994;73:424-431.

46 Hawk WA, Hazard JB. The many appearances of papillary carcinoma of the thyroid. Cleve Clin 1976;43: 207-215.

47 Schroder S, Bocker W, Dralle H et al. The encapsulated papillary carcinoma of the thyroid. A morphologic subtype of the papillary thyroid carcinoma. Cancer 1984;54:90-93.

48 Moreno A, Rodriguez JM, Sola J et al. Encapsulated papillary neoplasm of the thyroid: retrospective clinicopathological study with long term follow up. Eur J Surg 1996;162:177-180.

49 Jain M, Khan A, Patwardhan $N$ et al. Follicular variant of papillary thyroid carcinoma: a comparative study of 
histopathologic features and cytology results in 141 patients. Endocr Pract 2001;7:79-84.

50 Passler C, Prager G, Scheuba C et al. Follicular variant of papillary thyroid carcinoma: a long-term follow-up. Arch Surg 2003;138:1362-1366.

51 Lang BH, Lo CY, Chan WF et al. Classical and follicular variant of papillary thyroid carcinoma: a comparative study on clinicopathologic features and long-term outcome. World J Surg 2006;30:752-758.

52 Chang HY, Lin JD, Chou SC et al. Clinical presentations and outcomes of surgical treatment of follicular variant of the papillary thyroid carcinomas. Jpn Clin Oncol 2006;36:688-693.
53 Di Cristofaro J, Marcy M, Vasko V et al. Molecular genetic study comparing follicular variant versus classic papillary thyroid carcinomas: association of N-ras mutation in codon 61 with follicular variant. Hum Pathol 2006;37:824-830.

54 Yuksel O, Kurukahvecioglu O, Ege B et al. The relation between pure papillary and follicular variant in papillary thyroid carcinoma. Endocr Regul 2008;42: 29-33.

55 Gupta S, Ajise O, Dultz L et al. Follicular variant of papillary thyroid cancer: encapsulated, nonencapsulated, and diffuse: distinct biologic and clinical entities. Arch Otolaryngol Head Neck Surg 2012;138:227-233. 